any difficulty in seeing all the plates, while the indistinct vision and other clinical signs of digitalis intoxication had disappeared.

In acute suicidal digitalis poisoning we have found the colour vision test to be of no value, indicating that a certain time is needed for the development of the defect in colour vision. Similarly in cases of intoxication provoked by an apparent hypokalaemia the test has proved unsuitable.

The serum digoxin level of $1.3 \mathrm{ng} / \mathrm{ml}$ in of $2.0 \mathrm{ng} / \mathrm{ml}$ which is customarily regarded one of our patients was well below the level as the threshold for digitalis intoxication. However, even at such low digoxin levels cases of intoxication have been reported. ${ }^{1}$ Cardiac signs of digitalis intoxication are probably based on the inhibition of the transport-related ATPase. ${ }^{5}$ ATPases from various sources show different sensitivities towards inhibition by cardiac glycosides. ${ }^{6}$ It is tempting to assume that the ATPase of the eye may sometimes be even more sensitive than that of the heart, which would contribute to the visual complaints often encountered in digitalis intoxication.

In our study all the patients had been treated with digoxin for long periods when impaired colour vision was demonstrated. None of them was hypokalaemic. In all cases the heart disease and its treatment were fairly stable. In such cases the colour vision test can be used as an additional simple screening test for digitalis intoxication if any suspicion of overdosage is aroused.-I am, etc.,

First Department of Med:cine,

Vesa ManNinen

University of Helsinki,

Helsinki, Finland

Butler, V. P., jun., Progress in Cardiovascular Disea-es, $1972,14,571$

. 188.

Lely, A. H., and van Enter,

Gomez, A. L., American Heart foumal, 1972, 84,285 .

Okita, G. T. in Symposium on Digitalis, ed. $\mathrm{O}$

131.ein. S. N. Hauge and L. Storstein, $D$.

6 Repke, K, personal communication, 1973

\section{Diuretics in Hypertension}

SIR,-Duiretics are widely used in the treatment of hypertension, partly because they counteract the salt and water retention normally associated with effective reduction in blood pressure, but also because thiazides, at least, reduce peripheral vascular resistance through a direct action on arterioles. Dr. $\mathbf{H}$. J. Dargie and his colleagues (9 November, p. 316) confirm the view held by many that a routine potassium supplement is not necessary when a diuretic is given as an adjunct to the treatment of hypertension in otherwise healthy individuals taking a normal diet. Thus a substantial number of patients can be spared some tablets and the country a small expense.

If cost-effectiveness is to become an important factor in our therapeutic decisionmaking, as it should, we should also ask why the authors chose to use frusemide in this situation. Frusemide has been one of the most important therapeutic advances in the past 10 years for the treatment of resistant oedema and for left ventricular failure, but it does not to my knowledge have any proved advantage over thiazides in the treatment of hypertension-indeed, it may be less effective.1 ${ }^{2}$ The money saved by not giving a potassium supplement is small compared with the expense of choosing an appropriate diuretic. Can we not as prescribing doctors take note that a simple thiazide is at least as good as an other diuretic for the treatment of uncomplicated hypertension and that the cost of bendrofluazide $5 \mathrm{mg}$, for example, is one-quarter of the that of frusemide $40 \mathrm{mg}$ ? -I am, etc.

St. George's Hosp:tal,

Peter RichaRds

London S.W.1

1 Lancet, 1972, 1, 299.
2 Anderson, J., et al., Quarterly fournal of Medi-
cine, 1971, 40, 541.

Complications of Prostaglandin-induced Abortion

SIR,-I read with great interest the letter of Professors S. M. M. Karim and S. S Ratnam (19 October, p. 161) on cervical rupture during abortion induced by intraamniotic prostaglandins. The authors state rightly that this type of trauma is secondary to excessive uterine stimulation in the presence of unusual cervical resistance and that it is encountered mainly in young primigravidae. The lesion, however, is no limited to patients given $\mathrm{PGF}_{2} \propto$ as cases have already been reported after intraamniotic instillation of $\mathrm{PGE}_{2 .}{ }^{12}$ It is therefore unlikely that the latter compound exerts any protective action in this respect.

May I further point out that two very different lesions are encountered. The first one occurs-before any cervical dilatation has taken place-at the level of the thinnedout posterior isthmic wall. It presents as transverse tear through which fetus and placenta are expelled into the vagina. The tear may extend into the lateral aspects of the isthmic region, leading to partial annular detachment of the cervix. ${ }^{1}$ Even when repaired this lesion may fail to heal and a fistulous tract may develop, interfering with later reproductive performance. The complication can be prevented by examination of the cervix at regular intervals during the course of abortion and, in those cases at risk, by insertion of one or more laminaria tents into the cervical canal. ${ }^{34}$ In case of impending rupture gentle instrumental dilatation of the cervix should be performed immediately.

Very different and of less consequence is the longitudinal tear involving the lateral aspect of an insufficiently dilated cervix during expulsion of the conceptus. This lesion, somewhat comparable to a Dührssen's incision, is easier to repair and, if it does no reach the uterine isthmus, it should not be cause of cervical incompetence.

To the best of my knowledge not a single instance of either type of traumatic lesion to the cervix has been reported after extraamniotic administration of prostaglandins. It is possible that the Foley catheter, usually resorted to when use is made of this route, has a "ripening" effect on the cervix which facilitates dilatation.-I am, etc.,

Department of Obstetrics and Gynaeco'ogy,

J. J. AMY State University

1 Bowen-Simpkins, P., foumal of Obstetrics and Gunaecology of the British Commonwealth 2 Craft, I., Contemporary Ob/Gvn, April 1974. Corson, S. L., Bolognese. R. J., and Merola, J.,
American fournal of Obstetrics and Gynecology. 1973.117, 27

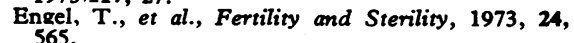

\section{Departmental "Research"}

SIR,-The Department of Health and Social Security has recently commissioned a "research" project to be carried out by Medical Surveys Ltd. I have just received the documents, which contain 20 complicated questions. I am supposed to provide detailed information about certain medical journals, including the British Medical fournal, Prescribers' fournal, Health Trends, Medicine, and the Lancet. I am supposed to answer such questions as how frequently I read these journals, which articles I read, how long I spend reading each journal, how I receive the copy, and what I do with it when I have read it, and many other childish questions which are insulting to one's intelligence.

I am indeed saddened that a member of the medical profession has so much time available to spend on such a useless and expensive exercise. Not only is it a waste of very limited financial resources, but it is this sort of thing which aggravates the acute shortage of paper. It seems to confirm my worst suspicion that the D.H.S.S. employs large numbers of medical administrators who find it hard to occupy their time. They will be well advised to return to the work for which they were trained.-I am, etc.,

London $\mathbb{W} .1$

Nigel H. HARRIS

\section{Place of Diagnostic Radiology in Medicine}

SIR,-I have just read the Langdion Brown Lecture by Dr. J. W. D. Bull (10 August, p. 394). May I reinforce from practical experience the enormous benefits of the many proposals in his thoughtful presentation?

In this new medical school in California radiology is taught almost from the day that the medical student enters the medical school, and it is taught by radiologists. They are in the anatomy class, in the dissecting room, and teaching physiology. (How better to learn how a patient swallows than to see a ciné film of a patient actually swallowing?) The anatomy of the chest, the appearance of the normal chest, and its pathology are taught by radiologists in close cooperation with their pulmonary medicine colleagues and the pathologists. One subject may be taught by all three in the same afternoon. In addition to anatomists and radiologists in the dissecting room there are the appropriate clinicians. A dissection of the knee becomes meaningful when there is an orthopaedic surgeon to answer questions and direct it and a radiologist to demonstrate how the average doctor will see it for the rest of his life.

In the hospital the same principle applies and in my department three or more conferences are held daily to review the films from different clinical areas. Radiologists are always available in the department and, moreover, decide what films are taken. They do not accept "orders" but examine "requests." By thus taking more responsibility they become better radiologists, more aware of what they are doing for their patients, and take more personal interest in the patients themselves. Almost the least important part of their work is the written report on the radiographs. Providing the clinicians with consultation and help follow- 